\title{
End Coercion in Mental Health Services-Toward a System Based on Support Only ${ }^{\dagger}$
}

\author{
Martin Zinkler ${ }^{1, *(D)}$ and Sebastian von Peter ${ }^{2}$ \\ 1 Department of Psychiatry, Psychotherapy and Psychosomatic Medicine, Kliniken Landkreis \\ Heidenheim gGmbH, Academic Teaching Hospital of Ulm University, Schlosshaustr, 100, \\ 89522 Heidenheim, Germany \\ 2 Medical School Brandenburg, Department of Psychiatry and Psychotherapy, Immanuel Albertinen \\ Klinik Rüdersdorf, Seebad 82/83, 15562 Rüdersdorf bei Berlin, Germany \\ * Correspondence: martin.zinkler@kliniken-heidenheim.de \\ † A German version of this paper is currently under review in the German journal "Recht \& Psychiatrie".
}

Received: 17 June 2019; Accepted: 21 August 2019; Published: 24 August 2019

\begin{abstract}
Based on the UN Convention on the Rights of Persons with Disabilities (CRPD), several UN bodies, among them the High Commissioner for Human Rights, have argued for a complete ban of all coercive interventions in mental health care. The authors conceptualize a system for mental health care based on support only. Psychiatry loses its function as an agent of social control and follows the will and preferences of those who require support. The authors draw up scenarios for dealing with risk, inpatient care, police custody, and mental illness in prison. With such a shift, mental health services could earn the trust of service users and thereby improve treatment outcomes.
\end{abstract}

Keywords: CRPD; human rights; coercion; social control; mental illness

\section{Introduction}

Based on the UN Convention on the Rights of Persons with Disabilities (CRPD) (United Nations 2018a), several UN bodies, among them the High Commissioner for Human Rights, have argued for a complete ban of all coercive interventions in mental health care (United Nations 2013, 2014, 2017a, 2017b, 2018b). In 2014, the Committee on the Rights of Persons with Disabilities called for states to "abolish policies and legislative provisions that allow or perpetrate forced treatment" (United Nations 2014), arguing that it is an "ongoing violation found in mental health laws across the globe, despite empirical evidence indicating its lack of effectiveness and the views of people using mental health systems who have experienced deep pain and trauma as a result of forced treatment."

According to the Committee, forced treatment violates Article 12 of the Convention, equal recognition before the law, and several other articles such as the right to personal integrity (Art. 17), freedom from torture (Art. 15) and freedom from violence, exploitation, and abuse (Art. 16). The Committee perceives forced treatment to deny the legal capacity of a person to choose medical treatment, therefore classifying it as a violation of Article 12 of the Convention (United Nations 2014).

The Committee is equally unambiguous about detention in mental health facilities: the denial of the legal capacity of persons with disabilities and their detention in institutions against their will, either without their consent or with the consent of a substitute decision-maker, is perceived to be an ongoing problem: "this practice constitutes arbitrary deprivation of liberty and violates articles 12 and 14 of the Convention. States parties must refrain from such practices and establish a mechanism to review cases whereby persons with disabilities have been placed in a residential setting without their specific consent." (United Nations 2014). 
Similarly, the 2017 report of the Special Rapporteur on the right of everyone to the enjoyment of the highest attainable standard of physical and mental health argues for "measures to radically reduce medical coercion and facilitate the move towards an end to all forced psychiatric treatment and confinement." (United Nations 2017b). Additionally, in 2017, the UN High Commissioner for Human Rights held that "many practices within mental health institutions also contravene articles 15, 16 and 17 of the Convention on the Rights of Persons with Disabilities. Forced treatment and other harmful practices, such as solitary confinement, forced sterilization, the use of restraints, forced medication and overmedication (including medication administered under false pretenses and without disclosure of risks) not only violate the right to free and informed consent, but constitute ill-treatment and may amount to torture." (United Nations 2017a). Consequently, this report supports the abolition of all involuntary treatment and the adoption of measures to ensure that health services including all mental health services are based on the free and informed consent of the person concerned, as stipulated by the UN Committee on the Rights of Persons with Disabilities and "the elimination of the use of seclusion and restraints, both physical and pharmacological." (United Nations 2017a).

All these postulations, however, are in stark contrast with the reality of mental health care. Even though mental health care practices and mental health law vary around the globe, they also share a long history of coercion, detention, rights violation, and detainment. Even if most current mental health care systems offer support of various intensity and degree, they also use coercive interventions (e.g., mechanical restraint (being tied to a bed frame); chemical restraint (being injected with tranquilizers); isolation (being locked in a room); detention in hospital or being brought to a mental health facility by the police with the use of force). The frequency and intensity of coercive interventions in mental health care vary (Kallert et al. 2005) and systematic recording is only in place in some countries (for a register on coercive interventions in Germany see (Flammer and Steinert 2018)).

The response from psychiatry has mainly been critical, defending the need for coercion and going as far as accusing the Committee of "reversing hard won victories in the name of human rights" (Freeman et al. 2015) or suggesting that governments "ignore the Convention when it would interfere with a commonsense approach to protecting citizens who in one way or another are incapable of protecting themselves." (Applebaum 2019).

A shift of mental health care away from coercion and toward a system based on support only was recently discussed as a possible scenario for the future of mental health care (Giacco et al. 2016; Priebe 2018) with an emphasis on a leading role of service users in service planning, service development, and service delivery. While there was no further indication of what such services would look like and what they would do, this scenario forms the basis of our paper: rather than discussing the rationale for or against coercion in mental health care, this paper will outline what coercion-free mental health care could look like and how mental health services could interact with other agents in certain situations. We will therefore start with an outline of the overall logic of a coercion free psychiatric support system. Then, we will describe the situations that typically lead to coercion in mental health care and elaborate on how this new way of mental health care will be different from the traditional support and coercion paradigm. We will argue that mental health care without coercion will not only comply with human rights standards, but will also improve care and treatment outcomes for the most vulnerable if a number of safeguards are introduced.

\section{Overall Logic of a Coercion-Free Psychiatric Support System}

The UN Committee on the Rights of Persons with Disabilities in its General Comment No. 1. infers from Article 12 of the Convention (Equal recognition before the law) a ban on all forms of substituted decision making (United Nations 2014). Traditionally, substituted decision making involves health care personnel, legal guardians, or family members. Instead, persons with disabilities should now be supported in their own decision-making as far as they opt to be supported (United Nations 2014).

Restrictions on their legal capacity based on an assumed impairment in mental capacity are no longer permitted. According to the CRPD, legal capacity "must be given to every individual by virtue 
of being human ( ... ) (and) recognizes that regardless of perceived or actual decision-making ability, every individual has a right to be respected as a full person before the law with rights, responsibilities and agency - this is the right to legal capacity on an equal basis." (Arstein-Kerslake and Flynn 2015). The task for health care professionals is to change to support only, based at the same time on the extent of the disability and on the will and the preferences of the person concerned.

The UN Committee does not provide a definition of will and preferences. The British psychiatrist Szmukler (Szmukler 2019) suggested in a recent edition of the Journal of the World Psychiatric Association of using the term preferences for making a choice from two or more alternatives. The will, in his view, represents a "higher order self-governing mechanism, one in which "values" play a key role and where desires are subject to forms of deliberation within higher-order 'policies' extending over time and expressing commitments towards ends that embody value." (Szmukler 2019). In this paper, we used less complex and perhaps more plausible definitions of will and preferences, even though they may be in contrast to Szmukler's definition. Preferences are attitudes developed over the life course, for example, the determination to stay alive despite setbacks with desperation and hopelessness. Will is then the will expressed in a particular moment, for example, "I want to be discharged from hospital.". The relevance of these different definitions of will and preferences are shown in Section 3.2.

The basic principles of a psychosocial support system that follows this interpretation of the Convention are solidarity and respect for self-determination (Zinkler et al. 2019). Solidarity means support from informal and institutional parts of society that aims for full participation in society. Depending on the extent of the disability, this may be informal support and counseling in minor impairments or wide-ranging and intensive support in severe impairments. Respect for self-determination involves the freedom of choice in the uptake of support, irrespective of the type or extent of the disability.

In this new system of assistance, offering certain types of institutional care (supported housing, social firms, hospital care) will not be sufficient as many people with psychosocial disabilities find these forms of assistance unsuitable for their needs or are ineffective. The task will be to develop ways of support that are regarded as helpful and effective by as many service users as possible.

Of particular significance are the preferences of those service users who have turned away from traditional mental health support and become victims of coercive care with detention in mental health facilities, seclusion, restraint, and coercive treatment (Zinkler and De Sabbata 2017). Effective assistance for these persons will depend on the ability of the system to meet their expectations. A person with a psychosocial disability may refuse to be diagnosed with a certain psychiatric disorder or may contest the notion of mental illness altogether. Even so, this person would not forfeit societal solidarity and assistance, for example, in a situation of desperation and homelessness. Support staff will then discuss with the person what kind of support can be agreed on.

Any type of support will depend on whether the person accepts a particular intervention. Even if the person declines the offered support, mental health and social services cannot abdicate their duty to support them, but will have to look for other means of support. This may require new forms of communication to elicit will and preferences as well as further individualization of support.

Even so, there will still be situations when a particular intervention or a set of interventions cannot be agreed upon. Some people will refuse assistance from mental health services even in dire circumstances. However, there are several reasons to assume that greater agreement on treatment and care will be reached in the new system:

(1) The interventions for support will be radically individualized and will move away from institutions to the community;

(2) Stigmatizing attributions of certain diagnoses (schizophrenia) or to certain groups (the mentally ill) can be avoided without losing access to support;

(3) The support system (mental health and social services) loses the deterrent effect of the traditional coercive interventions in psychiatry (detention, restraint, medication) and thereby wins the trust of those persons who turned away from the services for this particular reason; and 
(4) The support system will be obliged to look for new no-restraint interventions as soon as the traditional coercive interventions cannot be carried out anymore.

The conventional response from services ("we don't know what else to do, so we apply for detention in a mental health facility") will change to: "what can we do now to support this person, as our hitherto approach has been ineffective or was declined by the person?"

Renouncing coercive interventions enables the support system to learn and develop non-restraint interventions (Zinkler and Koussemou 2013; Zinkler 2016). Conceivably, the serious consequences of severe mental health problems like homelessness, family break-ups, and imprisonment would occur less frequently.

\section{Typical Situations of Coercion and Suggestions for Alternative Practices}

Coercive practices commonly emerge from circumstances within and outside of clinical psychiatry that can be classified into four typical scenarios:

(1) A person behaves in a way that suggests dangerousness arising from mental illness,

(2) A person in inpatient mental health care demands to be discharged,

(3) A person is in police custody and shows signs of mental illness, and

(4) A person with signs of mental illness is in prison and is to be removed to a mental health facility for treatment.

This listing largely regards the so called "hard cases" (Arstein-Kerslake and Flynn 2015). We are not suggesting the creation of special rules for these cases or the definition of some kind of last resort use of coercion or some "ultima ratio". In line with Arstein-Kerslake and Flynn, we believe in the principle, that "even in the hard cases, legislative response must apply equally to people with and without disabilities." (Arstein-Kerslake and Flynn 2015).

\subsection{Mental Illness and Dangerousness}

Traditionally, persons who in one way or another pose a danger to themselves or to others and in the eyes of their surroundings suffer from mental illness can be brought to a psychiatric hospital voluntarily or against their will. In many jurisdictions, the police perform this task. In the new system, however, the police lose the option to remove a person to a hospital against their will. A police officer may take someone in police custody, irrespective of an assumed or diagnosed mental illness, but they cannot take the person to a hospital against their will.

The police officer would then ask the person if they wanted to have a psychiatric consultation, speak to a counsellor or social worker, or be admitted to hospital. Only if the person agrees would consultation, counseling, or hospital admission be arranged. The intervention by a professional or peer support worker could take place in police custody or (if the person is released) at their home.

The principle of non-discrimination in the Convention stipulates that persons with an assumed or diagnosed mental illness must not be treated legally different than persons without this attribution. Accordingly, if there are legal grounds to keep the person in custody-irrespective of an attributed mental illness - they will be reviewed by a court of law. Again, a person with a suspected mental illness would be informed comprehensively about the services available including the option to be admitted to hospital, but also about the options for support while in custody, at home, or in a crisis center, etc.

To fulfill this role, police officers need information on mental and physical health assistance, financial assistance, assistance for homelessness, and for victims of crime. The officers would make contact with these services if the person agrees. Mental health services should have the capacity to assist 24/7 and counsel the person while in police custody.

Arguably, the most difficult task for mental health professionals lies in gaining the trust of persons who have experienced aversive or even traumatic (coercive) involvement with mental health services. 
Mental health professionals will then have to clarify first how they work, which is without coercion and discrimination. The World Health Organization has recently published a training manual on legal capacity in mental health services (WHO 2017), which could be a starting point for non-discriminatory and rights-based practice.

Whether the person accepts a diagnosis of mental illness is not a condition in which to receive support, for example, emergency accommodation or financial assistance to buy food. Whether or not a court of law decides on the deprivation of liberty, psychosocial assistance would be available. A court may find that the person is better served by being treated in hospital or at home. It may even decide to suspend custody if the person goes to hospital. However, the court cannot direct a transfer to hospital or oblige the person to treatment in the community. It may well impose certain non-discriminatory sanctions such as reporting to the police at certain intervals, or not to travel abroad.

The relation between the person concerned and the support system (mental health and social services) should always be based on informed agreement or informed dissent. Treatment and care cannot be determined anymore by a court or an administrative body (who may think that a particular intervention is just what the person needs).

A move toward this system will have to address the resistance of professionals in these contexts (police, prison, and hospital). The World Health Organization has developed a new training tool kit called "QualityRights" to "improve access to quality mental health and social services and promote the rights of people with mental health conditions, psychosocial, intellectual and cognitive disabilities." (www.who.int/mental_health/policy/quality_rights/en/). So far, this is available in English, French, Spanish, and Portuguese as a traditional face-to-face training manual and in English as online-training. Further translations will follow. Involving people with first-hand experience of mental illness in the training of police officers and prison staff has been found to be effective in Germany (Bock et al. 2015, 2019).

\subsection{Mental Illness in Hospital}

Currently, if a patient requests to be discharged from a psychiatric hospital and the medical team disagrees, an assessment takes place to see whether the mental state of the person and other circumstances justify keeping the person in hospital against their will. Determinations may be made on the level of perceived risk and the capacity of the person to decide for themselves. The findings of the assessment and the recommendation to keep the person in hospital will be discussed with the person, who then has the option to either remain in hospital "voluntarily" or become subject to a detention order for a certain duration, which is typically several weeks.

Instead, in the new system, a dialogue would begin with the person on their wish to be discharged and any problems that may emerge from the discharge in this situation. Mental health professionals will outline the support services available in the community. The whole process is guided by the will and the preferences of the patient. Only if their will and preferences cannot be determined, a "best interpretation of will and preferences" (United Nations 2014) can be used as a guide to decide on the appropriate support and treatment. In the first instance, the interpretation of will and preferences will be a task for the professionals concerned with a situation of psychosocial emergency, similar to emergency staff at the site of a road traffic accident dealing with an unconscious person, who will work on the assumption that it was an unintended accident. If a few hours later they find evidence that the accident was actually intended (a suicide note), the interpretation changes and requires closer attention. Relatives will be involved, and an ethics committee might be called to assist the medical team with their decisions to best reflect the person's will and preferences. If controversial interpretations emerge, a court may have to deal with the case. However, a determination by mental health professionals alone based on the "best interest" of the patient would no longer be permitted (United Nations 2018b).

There may be situations where the actual will and hitherto expressed preferences of the person point in different directions: a patient may say they want to end their life (actual will), however, up to this point in their life, they may not have given any indication that they wanted to die (hitherto 
preferences). A court may then be required to order the person to remain in hospital for a few hours until their will and preferences are determined. This process can be assisted by family members or friends and will include information and recommendations on all support options available in the community, ideally including $24 \mathrm{~h}$ assistance at home (Zinkler et al. 2019).

Szmukler (2019) suggested looking at will as a "person's deep beliefs, values or personal conception of the good" as opposed to their actually expressed preferences. He seems to confer more weight to the former, particularly if a will formulated at time 1 is inconsistent with the preferences stated at time 2 . We argue that lending more weight to a "person's deep beliefs, values, or personal conception of the good", and thereby disregarding the actual will (according to our definition) of a person in relation to a given situation, risks ignoring the discontinuities in their personal development and thereby interfere with legal capacity. In our opinion, legal capacity has to include the option to change both one's will and preferences at any time. In our view, in a situation where will and preferences point in different directions, professionals should support the person in finding a synthesis that pays reference to both their will and preferences, rather than act as the arbiter between the two.

Szmukler's argument (Szmukler 2019) about the will as a "higher-order motivating structure" and a "reason-giving force" moves the will close to a functional approach to the capacity that one possesses or not at times of mental illness, and thereby a structure that can be assessed by others as giving reason or not giving reason, or as a higher order (as opposed to a lower order preference). Whether intended or not by Szmukler, this seems to be the point where the critique of the UN Committee on the Rights or Persons with Disabilities sees a "flawed concept" (United Nations 2014), which undermines legal capacity.

Instead, the task for mental health professionals would be to support autonomy by determining the will and preferences of the person and by assisting them if possible. This includes an explanation of support options to enable the person to decide for themselves. Trust-building communication will be essential: "We are here to support you and we will not force you to do anything you don't want." Emotional understanding can be used: "No wonder you despaired, considering what you are going through at the moment" as well as counseling on the support services: "Did you know that we offer crisis intervention at your home with staff who have been through mental health problems themselves?"

If their will and preferences point toward discharge from hospital, the person will be discharged irrespective of any considerations regarding diagnosis, capacity, or risk. The type and intensity of the support offered at discharge will, of course, be determined by the severity and individual aspects of the person's mental health.

Traditionally, hospital staff often said: "We cannot help you if you don't allow us to treat you." If the person refused the treatment, they were discharged or detained in hospital. In the new system, support would start with the question: "What do you need, what can we do for you?" Human and social assistance will take priority over psychiatric considerations regarding diagnosis or mental capacity.

Decision-making skills may be impaired to the extent that the person does not know what to decide or does not know the options, or cannot, at least not conventionally articulate her will and preferences. Careful explanation, or just taking more time, are possible options to overcome this and still arrive at a determination of their will and preferences. A person close to the person concerned may be used as an "interpreter" if they have developed means of communication (e.g., the mother of an adult with hearing difficulties and intellectual impairment). Mental health advocates, ideally persons with first-hand experience of mental illness, may be able to support communication in situations of extreme mental states.

\subsection{Police Custody and Mental Illness}

Most jurisdictions allow the police to forcibly remove a person from a public place to a psychiatric hospital. This practice discriminates persons with presumed mental illness, as the removal rests on the presumption of mental illness. Therewith, the law treats persons with an assumed mental illness 
differently than other persons. Based on the assumption of a mental illness, the person has to see a doctor or some other mental health professional in the community or at a hospital. The outcome of the assessment may then lead to detention in hospital.

However, according to the interpretation of the Convention by the UN Committee (United Nations 2014), such measures can only be taken with the consent of the person. This raises the question of how the new non-discriminatory system would deal with a police call to a person assumed to be mentally ill. What will happen when the police want to involve mental health services?

As long as the person agrees to see a doctor or be taken to hospital, these steps can be taken. However, what happens if the person rejects these proposals? Equality before the law (Article 12 of the Convention) stipulates that the person with a presumed or diagnosed mental illness has the same rights as any other person. The person may be taken into police custody only if the general criteria (those not related to mental illness) for police custody are fulfilled. If thereafter, the general criteria to remain in custody are fulfilled, the case could be decided by a judge, as with any other person.

Mental health and social services should be on stand-by to see this person, if they agree, to explain the support available such as counseling while in custody, a crisis home after release from custody, home treatment, or hospital admission. A judge may well decide to release the person if they are satisfied that one of the support options is more reasonable than keeping the person in custody. However, judicial decisions will remain strictly separated from psychosocial support and cannot compel the person to accept any particular kind of support. Whether the person takes up any support from mental health services is for them to decide.

One might argue that such a change would bring more people with established or suspected psychiatric diagnoses into police custody, because they cannot be taken to hospital against their will and would remain in custody until a judge decides on the rightfulness of their confinement. However, just the opposite may occur when more people agree to treatment in hospital once they realize their rights will be respected and they can terminate treatment at any time.

The willingness of a person to accept psychosocial support may influence judicial decisions on the deprivation of liberty. This may or may not be advantageous for the person in comparison to a custodial approach; however, it will be for the judge (or a tribunal) to decide and should not be based on the recommendations of a psychiatrist. Rather, the task of the psychiatrist will be to support the person in arriving at a decision about accepting or refusing psychosocial support.

In contrast with the current system, the psychiatrist should support the decision-making of the person and not the decision-making of the judge. Should a judge (or a tribunal) require a psychiatric assessment, this assessment should be strictly separated from psychosocial support to protect the trusting relationship between the person and their support team. Naturally, it will be up to the person themselves as to whether they consent to an assessment by an independent psychiatrist.

\subsection{Mental Illness in Prison}

It follows from the arguments outlined above that decisions on psychosocial support and treatment for persons remanded or sentenced in prison will follow their will and preferences. Judicial determinations on remand in prison or on prison sentences must not discriminate persons with an assumed or diagnosed mental illness. Therefore, the duration of imprisonment for someone with a diagnosed mental illness must not be longer than for someone without a diagnosis (for a comparable offence). Likewise, for people with mental illness, the curtailments of liberty in prison should not be harsher than for those without mental illness.

This will imply changes in the legal norms governing the interface of criminal justice and psychiatry. First, in-patient psychiatric treatment for offenders can only be arranged if it follows the will and preferences of the person concerned.

Second, for an offender with a mental illness, the time spent in hospital under curtailments of liberty must not be longer than the prison sentence for a person with a similar offence, but without a diagnosed mental illness. 
Mental health and social services will need to be boosted to offer prison visits and arrange social support, counseling, and treatment during the time spent in prison including psychotherapy. Crisis teams will offer the same service for prison inmates as they do in the community.

Judicial decisions on privileges in prison or on early release may take account of the person's willingness to accept treatment or on the course of their treatment. Reports on progress in treatment will be given to the person (not to the courts) so that they can decide whether they want to make these available to the court. Similar to the procedure stated above, a court may request an independent psychiatric report, not from the treating team, but from an independent expert in order to uphold treatment confidentiality and trust between the patient and their treatment team. Whether the independent expert can use treatment records for their report will be up to the patient to decide.

\section{Conclusions}

The UN Convention is more than just considering the will and preferences of individuals with impairments; it is about their most basic needs and human dignity, as laid out in the Preamble and several Articles such as 1, 3, 8, 16, and especially 25. According to the UN Committee on the Rights of Persons with Disabilities and several other UN bodies including the High Commissioner for Human Rights, coercive practice in mental health services is not in line with Article 12 and several other articles of the Convention. Changes in mental health practice toward a system based only on support are possible and can be conceptualized. The principles of mental healthcare will change as it loses its coercive interventions and therefore its function as an agent of social control. At the same time, supportive practice will develop and broaden across the whole interface of psychiatry and law enforcement. Intensity and form of support will always follow the will and the preferences of the person concerned.

In the new system, a psychiatric diagnosis will not lead to disadvantages concerning restrictions of liberty. A functional approach toward mental capacity will no longer be used to justify detention or coercive interventions. Legal sanctions for the individual follow a non-discriminatory process that applies to all members of society.

Psychosocial services will be more supportive in an environment where the person wants to be supported: at home, in a crisis center, at a friend's place, in the public, in police custody, in hospital, or in prison. Support and treatment should be open-access around the clock, so that hospital admission will no longer be used as the default option when no other support is available.

Resources previously used for coercive mental health care in hospital can, and should, be shifted to outreach-work in the community and in-reach-work in prison and police custody. Individualizing care plans according to will and preferences should ensure that fewer people remain without adequate support.

There are a number of safeguards to accompany this shift. Without a clear definition of their role and their responsibilities, mental health services tend to gravitate toward those who are less severely disabled, more able to pay for their treatment, more willing to accept treatment, and are more willing to follow traditional paths of mental healthcare, for example, going to an office to talk and to get a prescription. Once mental health services lose their dual function of support and social control, they will need to be geared to support those who are least able to support themselves. This can and should be achieved through clear rules on their function and their target population.

The funding of mental health services may be questioned once they relinquish the function of social control, if governments wonder why they should invest in services that do not remove "dangerous people" from the street. This will test the commitment of societies and health care agencies to support people without coercing them. For psychiatrists, it will test their willingness to give up power and face their own anxieties without resorting to control and restraint.

In order not to be stripped of resources, mental health services and research bodies will have to prove their determination and capacity to reach out to people who end up in police custody, 
are homeless, or in prison. Suitable outcome indicators of this commitment could be the number of people seen in custody, their physical health, and their willingness to be supported in the community.

Some people suffer from the stigma of a disability and the community they reside in often turns their backs on them. Where the will and preferences of the individual point to institutional care rather than individualized community support, this will also need to be taken on board. We do not suggest that there will no longer be a place for institutions. They may still play a role as temporary asylums for those who prefer this type of care on a strictly voluntary basis; all the while, the option to live in an institution should not depend on the ability to pay.

At the same time, there is much to gain in the relationships between users and professionals in mental health and social services with the change toward one based more on trust if the message is: "You can be absolutely sure that we will not undertake anything contrary to your will and preferences." Mental health and social services will be exclusively responsible to the person concerned, in particular, in their interface with law enforcement. Information about consultation, support, and treatment will not be passed on to anyone without the consent of the person.

Some of these tasks are well established in mental health care, others will be new when long-trodden paths like detention in hospital and coercive treatment are closed off. This change should trigger research efforts and learning in the system toward non-coercive support interventions. Communication between support services and persons with disabilities could benefit enormously. This holds the potential to improve treatment outcomes, particularly in people with severe mental illness.

Author Contributions: M.Z. conceived the idea of the paper and wrote the first draft of the manuscript. S.v.P. commented and redrafted. M.Z. and S.v.P. contributed to the final version of the manuscript.

Funding: This research received no external funding.

Conflicts of Interest: The authors declare no conflicts of interest.

\section{References}

Applebaum, Paul S. 2019. Saving the UN Convention on the Rights of Persons with Disabilities-From itself. World Psychiatry 18: 1-2. [CrossRef] [PubMed]

Arstein-Kerslake, Anna, and Eilionóir Flynn. 2015. The General Comment on Article 12 of the Convention on the Rights of Persons with Disabilities: A roadmap for equality before the law. The International Journal of Human Rights 20: 471-90. [CrossRef]

Bock, Thomas, Sarah Niemann, Robert Dorner, Anna Makowski, Helmut Fabeck, Candelaria Mahlke, Hans-Jochim Meyer, and Asmus Finzen. 2015. Wenn Stigma tödlich wird, kann Fortbildung lebensrettend sein-Zur konstruktiven Wirkung trialogischer Fortbildung bei der Hamburger Polizei. Psychiatrische Praxis 42: 278-80.

Bock, Thomas, Kim Sander, Angela Franke, Regina Linsig, André Rudel, Gwen Schulz, Vladimir Vahovic, and Kolja Heumann. 2019. Was macht die Seele im Knast? Trialogische Fortbildung zum Thema psychischer Gesundheit/Krankheit für werdende Justizvollzugsbeamte. Recht \& Psychiatrie 37: 20-25.

Flammer, Erich, and Tilman Steinert. 2018. The Case Register for Coercive Measures according to the Law on Assistance for Persons with Mental Diseases of Baden-Wuerttemberg: Conception and First Evaluation. Psychiatrische Praxis. [CrossRef]

Freeman, Melvyn Colin, Kavitha Kolappa, Jose Miguel Caldas de Almeida, Arthur Kleinman, Nino Makhashvili, Sifiso Phakathi, Benedetto Saraceno, and Graham Thornicroft. 2015. Reversing hard won victories in the name of human rights: A critique of the General Comment on Article 12 of the UN Convention on the Rights of Persons with Disabilities. Lancet Psychiatry 2: 844-50. [CrossRef]

Giacco, Domenico, Michaela Amering, Victoria Bird, Thomas Craig, Giuseppe Ducci, Jürgen Gallinat, Steven George Gillard, Tim Greacen, Phil Hadridge, Sonia Johnson, and et al. 2016. Scenarios for the future of mental health care: A social perspective. Lancet Psychiatry 4: 257-60. [CrossRef]

Kallert, Thomas W., Matthias Glöckner, Georgi Onchev, Jiří Raboch, Anastasia Karastergiou, Zahava Solomon, Lorenza Magliano, Algirdas Dembinskas, Andrzej Kiejna, Petr Nawka, and et al. 2005. The Eunomia project on coercion in psychiatry: Study design and preliminary data. World Psychiatry 4: 168-72. 
Priebe, Stefan. 2018. Where can psychiatry go from here? Nervenarzt 89: 1217-26. [CrossRef]

Szmukler, George. 2019. "Capacity", "best interests", "will and preferences" and the UN Convention on the Rights of Persons with Disabilities. World Psychiatry 18: 34-41. [CrossRef] [PubMed]

United Nations. 2013. Human Rights Council. Twenty-Second Session. Report of the Special Rapporteur on Torture and Other Cruel, Inhuman or Degrading Treatment or Punishment. A/HRC/22/53. Edited by Juan E. Méndez. New York: United Nations.

United Nations. 2014. Committee on the Rights of Persons with Disabilities. Eleventh Session. General Comment No. 1. Article 12: Equal Recognition before the Law. CRPD/C/GC/1. New York: United Nations.

United Nations. 2017a. United Nations. 2017a. Human Rights Council, Thirty-Fourth Session. Mental Health and Human Rights. Report of the United Nations High Commissioner for Human Rights. A/HRC/34/32. New York: United Nations.

United Nations. 2017b. Human Rights Council, Thirty-Fifth Session. Report of the Special Rapporteur on the Right of Everyone to the Enjoyment of the Highest Attainable Standard of Physical and Mental Health. A/HRC/35/21. New York: United Nations.

United Nations. 2018a. Convention on the Rights of Persons with Disabilities. Available online: https://www.un. org/development/desa/disabilities/convention-on-the-rights-of-persons-with-disabilities.html (accessed on 30 December 2018).

United Nations. 2018b. Human Rights Council, Thirty-Seventh Session. Report of the Special Rapporteur on the Rights of Persons with Disabilities. A/HRC/37/56. New York: United Nations.

WHO. 2017. Protecting the Right to Legal Capacity in Mental Health and Related Services—Who Quality Rights Training to Act, Unite and Empower for Mental Health (Pilot Version). WHO/MSD/MHP/17.5, Licence: CC BY-NC-SA 3.0 IGO. Geneva: World Health Organization.

Zinkler, Martin. 2016. Germany without Coercive Treatment in Psychiatry-A 15 Month Real World Experience. Laws 5: 15. [CrossRef]

Zinkler, Martin, and Kevin De Sabbata. 2017. Supported decision making and coercive treatment in severe mental Illness-A case study. Recht E Psychiatrie 35: 207-12.

Zinkler, Martin, and Jose Marie Koussemou. 2013. Germany's Federal Constitutional Court rules against compulsory medication-Three case reports. Recht E Psychiatrie 31: 76-79.

Zinkler, Martin, Candelaria Mahlke, and Rolf Marschner. 2019. Selbstbestimmung und Solidarität-Unterstützte Entscheidungsfindung in der Psychiatrischen Praxis. Köln: Psychiatrie Verlag.

(C) 2019 by the authors. Licensee MDPI, Basel, Switzerland. This article is an open access article distributed under the terms and conditions of the Creative Commons Attribution (CC BY) license (http://creativecommons.org/licenses/by/4.0/). 